\title{
Pelatihan Penulisan Naskah Drama dari Cerita Lisan Sulawesi Selatan di MTs Negeri 2 Biringkanaya Makassar
}

\author{
Muliadi1 \\ Universitas Muslim Indonesia, muliadi.muliadi@umi.ac.id \\ Kasma F. Amin² \\ Universitas Muslim Indonesia, f.aminkasma@gmail.com \\ Umar Mansyur ${ }^{3}$ \\ Universitas Muslim Indonesia, umar.mansyur@umi.ac.id
}

\begin{abstract}
Abstrak
Potensi kekayaan daerah berupa sastra lisan di Sulawesi Selatan sepenuhnya belum digali dan disebarluaskan kepada generasi muda. Potensi budaya ini dapat dijadikan sebagai sarana pembentukan karakter siswa di sekolah melalui kegiatan penulisan naskah drama. Kegiatan pelatihan penulisan naskah drama dari cerita lisan Sulawesi Selatan di MTs Negeri 2 Biringkanaya Makassar dilakukan dengan menggunakan metode pelatihan, pendampingan, dan praktik penulisan. Jumlah peserta pelatihan sebanyak 36 orang. Kegiatan ini dijalankan dalam beberapa tahapan, yakni persiapan, pelaksanaan, dan evaluasi. Pada tahap persiapan, dilakukan koordinasi dengan mitra, menunjuk tim pendamping, dan mempersiapkan materi pelatihan, serta memastikan kesiapan alat dan bahan penunjang pelatihan. Pada tahap pelaksanaan, tim menyampaikan materi pelatihan peserta. Setiap kelompok diberikan bahan sastra lisan dari daerah Sulawesi Selatan, yang selanjutnya akan disusun ke dalam sebuah naskah drama. Pada tahap evaluasi, tim pelaksana melakukan monitoring dan evaluasi mengenai tingkat pengetahuan mitra setelah kegiatan pelatihan dan pendampingan dilakukan. Secara keseluruhan, pelaksanaan kegiatan PKM Pelatihan Penulisan Naskah Drama dari Cerita Lisan Sulawesi Selatan yang dilaksanakan di MTs Negeri 2 Biringkanaya Makassar ini mendapat respons yang baik dari peserta yang menjadi mitra pengabdian masyarakat. Para siswa yang menjadi peserta pelatihan antusias mengikuti kegiatan yang diberikan.
\end{abstract}

Kata Kunci: penulisan, naskah drama, cerita lisan

\begin{abstract}
The potential of regional wealth in the form of oral literature in South Sulawesi has not been explored and disseminated to the younger generation. This cultural potential can be used as a means of forming the character of students in schools through drama script writing activities. Drama Script Writing Training Activities from South Sulawesi Oral Stories at the MTs Negeri 2 Biringkanaya Makassar were carried out using training methods, mentoring, and writing practices. The number of trainees is 36 people. This activity is carried out in several stages, namely preparation, implementation, and evaluation. In the preparation stage, coordination is carried out with partners, appointing a support team, and preparing training materials, and ensuring the availability of training tools and support materials. At the implementation stage, the team presents the participants' training materials. Each group is given oral-literary material from the South Sulawesi region, which will then be arranged into a drama script. In the evaluation phase, the implementation team monitors and evaluates the level of knowledge of partners after the training and mentoring activities are carried out. Overall, the implementation of the PKM Drama Script Writing Training from the South Sulawesi Oral Story which was held at MTs Negeri 2 Biringkanaya Makassar received a good response from participants who were community service partners. The students who participated in the training enthusiastically participated in the activities provided.
\end{abstract}

Keywords: writing, drama script, oral story 


\section{Pendahuluan}

Salah satu upaya meningkatkan mutu pendidikan adalah dengan menumbuhkan kegiatan literasi di bidang sastra untuk memacu siswa agar terampil menulis, membaca, dan bercerita sastra. Secara umum, kegiatan literasi sastra di sekolah dapat diwujudkan dalam bentuk kegiatan menyimak, berbicara, membaca, dan menulis. Keempat bidang berbahasa dan bersastra tersebut dapat dikembangkan sesuai dengan arah program literasi yang dicanangkan pemerintah, seperti menulis cerita, menyimak sastra lisan, membaca karya fiksi, dan kegiatan bercerita tentang sastra legenda yang ada di daerah.

Bacaan paling sederhana yang dapat diberikan kepada peserta didik adalah cerita lisan atau cerita legenda daerah. Hal ini dilakukan guna memancing minat baca siswa, karena ide dan latar cerita yang diberikan memiliki kaitan historis dengan lingkungan siswa. Selain karena dapat menumbuhkan minat membaca siswa, sastra menurut Budiharto \& Ramadani (2018) juga mempunyai peranan penting dalam meningkatkan kepedulian anak-anak terhadap lingkungan di mana mereka berada.

Namun demikian, tidak dapat mungkiri bahwa tingkat literasi masyarakat, khususnya peserta didik, tergolong masih sangat rendah. Peringkat minat baca Indonesia berdasarkan World's Most Literate Nations Ranked tahun 2016 menempatkan Indonesia di peringkat 60 dari 61 negara yang disurvei (Mansyur, 2019). Indonesia hanya unggul dari Botswana, sebuah negara bekas jajahan Inggris yang terletak di Benua Afrika. Lebih lanjut, untuk tingkatan peserta didik, skor hasil Programme for International Student Assessment (PISA) untuk tahun 2018, peringkat Indonesia di bidang literasi (reading) semakin merosot ke peringkat 74 dari 79 negera yang berpartisipasi (OECD, 2019).

Rendahnya kemampuan literasi para siswa, khususnya menulis sastra, tercermin dari kurangnya minat siswa terhadap membaca karya sastra. Hal ini juga menjadi salah satu persoalan yang dihadapi Madrasah Tsanawiyah (MTs) Negeri 2 Biringkanaya Makassar saat ini, yakni masih kurangnya kegiatan literasi sastra di sekolah, berupa menulis cerita atau naskah drama. Siswa tidak memiliki wadah untuk menuangkan ide dan pikiran kreatif mereka. Para siswa cenderung hanya menggunakan waktu luang di sekolah untuk kegiatan yang tidak bermanfaat. Sementara, menurut Mansyur (2018), minat baca itu berkaitan dengan kemampuan membaca, kebutuhan, lingkungan, dan juga tersedianya bahan bacaan memadai.

Maka dari itu, melalui Program Kemitraan Masyarakat (PKM), tim pelaksana mengadakan kegiatan apresiasi sastra dengan melakukan kegiatan pelatihan penulisan naskah drama yang diambil dari cerita lisan. Para guru Bahasa dan Sastra Indonesia juga dilibatkan dalam kegiatan ini agar memperkaya pengetahuannya tentang sastra lisan, sehingga nantinya juga dapat membimbing pengembangan karakter para siswa sebegai generasi muda yang bermanfaat di tengah masyarakat. Hal ini senada dengan Rohinah (2011) bahwa peran sastra dalam masyarakat dapat membentuk generasi masa depan yang berguna dan menjadi anggota masyarakat yang baik dan berguna dalam kehidupan.

PKM ini dilaksanakan di MTs Negeri 2 Biringkanaya. Sekolah ini berada di Kecamatan Biringkanaya, Kota Makassar, Provinsi Sulawesi Selatan. Kecamatan Biringkanaya merupakan wilayah pinggiran Kota Makassar dan berbatasan langsung 
dengan Kabupaten Maros yang memiliki beragam cerita lisan yang melimpah. Menurut Amin (2016), beberapa cerita lisan yang ada di Kabupaten Maros di antaranya Toakkala, I Nyunyi, Pattunuang Asue, Gua Mimpi, Ikan Keramat Penghuni Mata air Bantimurung, Bujung Liang, dan Kampung La Buaja. Sastra legenda banyak mengandung pendidikan moral sehingga penanaman nilai-nilai moral sejak dini dapat dilakukan para guru melalui pengetahuan tentang cara menulis naskah drama.

Hingga saat ini, potensi kekayaan daerah berupa budaya dan sastra berupa sastra lisan dan legenda yang ada di Sulawesi Selatan belum digali dan disebarkan secara luas kepada para generasi muda, khususnya kepada peserta didik di sekolahsekolah yang di Kota Makassar. Kekayaan budaya yang ada di daerah, khususnya di Kabupaten Maros, belum mampu dieksplorasi dan dikembangkan oleh para generasi muda secara kreatif. Padahal, pemahaman generasi muda akan nilai-nilai budaya dan sastra daerah sangat penting sebagai sarana pembentukan karakter (Muliadi, Firman, \& Amin, 2019). Selain itu, juga sebagai upaya pewarisan dan pemertahanan budaya dan sastra yang ada di Provinsi Sulawesi Selatan. Kabupaten Maros menyimpan berbagai macam cerita lisan atau legenda yang dapat dijadikan sebagai bahan penulisan naskah drama. Potensi ini dapat dijadikan sebagai sarana pembentukan karakter siswa di sekolah melalui kegiatan apresiasi sastra dalam bentuk penulisan atau pementasan drama.

Berdasarkan observasi awal yang dilakukan di MTs Negeri 2 Biringkanaya Makassar menunjukkan fakta bahwa mayoritas siswa belum terlalu mengetahui cerita-cerita lisan yang ada di Sulawesi Selatan, khususnya di Kabupaten Maros. Padahal melalui cerita lisan dan legenda dapat ditanamkan rasa kecintaan dan kebanggaan atas daerahnya. Upaya untuk melestarikan cerita lisan di Sulawesi Selatan salah satunya dapat dilakukan dengan cara mengangkat cerita lisan dan sastra legenda ke dalam naskah drama. Mengingat sesungguhnya drama dapat dijadikan sebagai media penanaman rasa cinta dan sarana untuk mewarisan budaya dan karya sastra daerah kepada generasi muda.

\section{Metode}

Pelaksanaan kegiatan PKM Penulisan Naskah Drama dari Cerita Lisan Sulawesi Selatan di MTs Negeri 2 Biringkanaya Makassar dilakukan dengan menggunakan metode pelatihan, pendampingan, dan praktik penulisan. Jumlah peserta pelatihan sebanyak 36 orang yang selanjutnya dipecah ke dalam 6 kelompok. Masing-masing kelompok akan didampingi oleh pendamping atau instruktur, baik dari dosen sebagai tim pelaksana, dan beberapa mahasiswa akhir Program Studi Sastra Indonesia yang sudah terlatih di bidang penulisan naskah drama.

Kegiatan PKM ini dijalankan dalam beberapa tahapan, yakni persiapan, pelaksanaan, dan evaluasi. Pada tahap persiapan, dilakukan koordinasi dengan mitra dan mempersiapkan dokumen administrasi penunjang, menunjuk mahasiswa yang akan menjadi pendamping, mempersiapkan dan menyusun bahan dan materi pelatihan, serta memastikan kesiapan alat dan bahan penunjang pelatihan. Pada tahap pelaksanaan, tim pelaksana memberikan pengarahan para pendamping. Tim menyampaikan materi pelatihan kepada guru dan siswa. Selanjutnya, kegiatan pendampingan kegiatan menulis naskah drama dilakukan sesuai dengan kelompok 
yang telah ditentukan. Setiap kelompok diberikan bahan sastra lisan dari daerah Sulawesi Selatan, yang selanjutnya akan disusun ke dalam sebuah naskah drama. Pada tahap evaluasi, tim pelaksana melakukan monitoring dan evaluasi mengenai tingkat pengetahuan mitra setelah kegiatan pelatihan dan pendampingan dilakukan.

\section{Hasil dan Pembahasan}

Sebelum turun ke lokasi mitra masyarakat, tim pelaksana terlebih dahulu melakukan pelatihan kepada mahasiswa di kampus untuk menjaring calon instruktur atau pendamping penulisan naskah drama dalam kegiatan pelatihan. Tim Pelaksana melakukan pelatihan atau bimbingan kepada para pendamping (mahasiswa) tentang teknik mengubah cerita lisan ke dalam tulisan naskah drama. Sehubungan dengan kegiatan ini, tim pelaksana menyajikan contoh cerita dari bentuk prosa kemudian digubah ke dalam bentuk naskah drama, dan setelah itu mahasiswa (calon pendamping) ditugasi untuk mengubah cerita prosa ke dalam bentuk drama. Dengan adanya kegiatan ini, para mahasiswa memiliki pengetahuan dan pemahaman yang cukup dan merasa percaya diri melaksanakan pendampingan penulisan naskah drama dari cerita lisan di MTs Negeri 2 Biringkanaya Makassar. Hasil pelatihan tersebut menjadi pengetahuan yang sangat berarti bagi para mahasiswa sebelum terjun ke lapangan (sekolah).

Kegiatan Program Kemitraan Masyarakat (PKM) yang dilaksanakan di MTs Negeri 2 Biringkanaya Makassar dilaksanakan selama 3 hari, yakni pada tanggal 5 November sampai dengan 7 November 2019. Setiap hari dilakukan bentuk kegiatan yang berbeda, sesuai dengan perencanaan dan metode yang dipersiapkan. Tim pelaksana menjalankan kegiatan dalam dua bentuk program prioritas, yakni prioritas utama dan prioritas penunjang. Pada bagian kegiatan prioritas utama dilakukan pengumpulan sebanyak mungkin cerita lisan dan sastra legenda daerah Sulawesi Selatan sebagai bahan penulisan naskah drama.

Setelah itu, di hari pertama, tim pelaksana mengadakan pelatihan kepada 36 peserta mengenai peran sastra dalam menumbuhkan pendidikan karakter siswa di sekolah dan juga mengenai pemanfaatan sastra lisan dan legenda daerah sebagai bahan penyusunan naskah drama. Agar lebih meriah, tim mengadakan kompetisi bercerita berdasarkan naskah drama yang telah mereka susun, sehingga memacu kreativitas dan keterampilan siswa dalam bercerita dan menyimak cerita lisan.

Pada bagian kegiatan penunjang, ditanamkan kepada para siswa rasa cinta pada karya sastra, terutama cerita lisan dan legenda lokal yang berasal dari Provinsi Sulawesi Selatan. Hal ini dilakukan sebagai program pembinaan dan pelestarian cerita lisan sebagai kearifan lokal masyarakat Sulawesi Selatan. Setelah naskah selesai, naskah drama dikumpulkan dalam bunga rampai atau kumpulan naskah drama hasil karya siswa.

Pelaksanaaan kegiatan PKM pelatihan penulisan naskah drama dilaksanakan dengan menggunakan model menulis naskah drama secara berkelompok. Peserta terdiri atas 36 orang yang terbagi ke dalam enam kelompok. Sebelum instruktur atau pendamping yang sudah terlatih menugaskan para siswa menyusun naskah drama, terlebih dahulu disajikan contoh cerita, cara dan kiat-kiat mengubah sebuah cerita lisan ke dalam sebuah naskah drama agar para siswa lebih mudah memahaminya. 
Alokasi waktu dalam menyusun naskah drama ditentukan oleh tim pelaksana agar masing-masing kelompok siswa dapat menyelesaikan kegiatan sesuaikan dengan perencanaan.

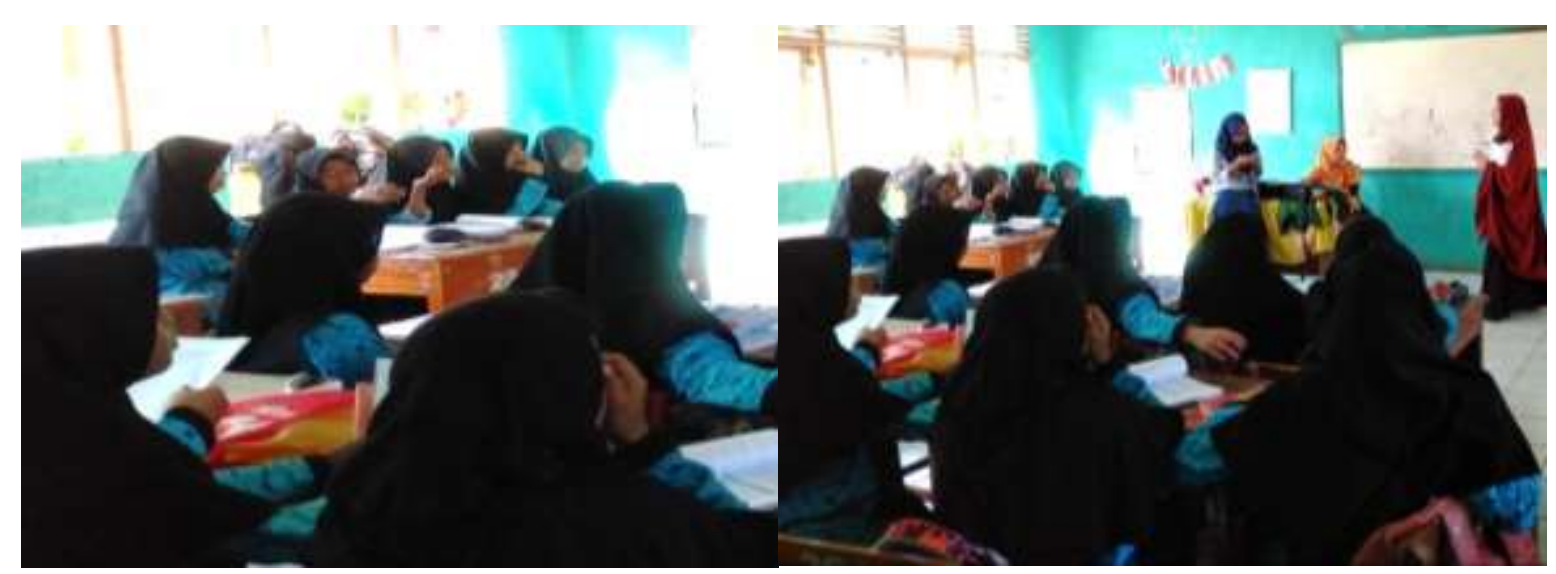

Gambar 1. Suasana pelatihan penulisan naskah drama

Pada kegiatan pendampingan penulisan naskah drama, para siswa diberikan cerita lisan oleh tim pendamping pada setiap kelompok. Beberapa cerita lisan dari daerah Sulawesi Selatan yang diberikan seperti Badai Modena, Toakkala, Hikayat Chip Peng, I Nyunyi, dan Meong Palo. Sebelum setiap kelompok diperdengarkan cerita daerah tersebut, instruktur memberikan contoh naskah drama yang telah diubah dari cerita lisan sebagai bahan pengayaan. Selanjutnya, instruktur kemudian memberikan instruksi kepada siswa untuk menyusun naskah drama dari cerita lisan yang telah diperdengarkan.
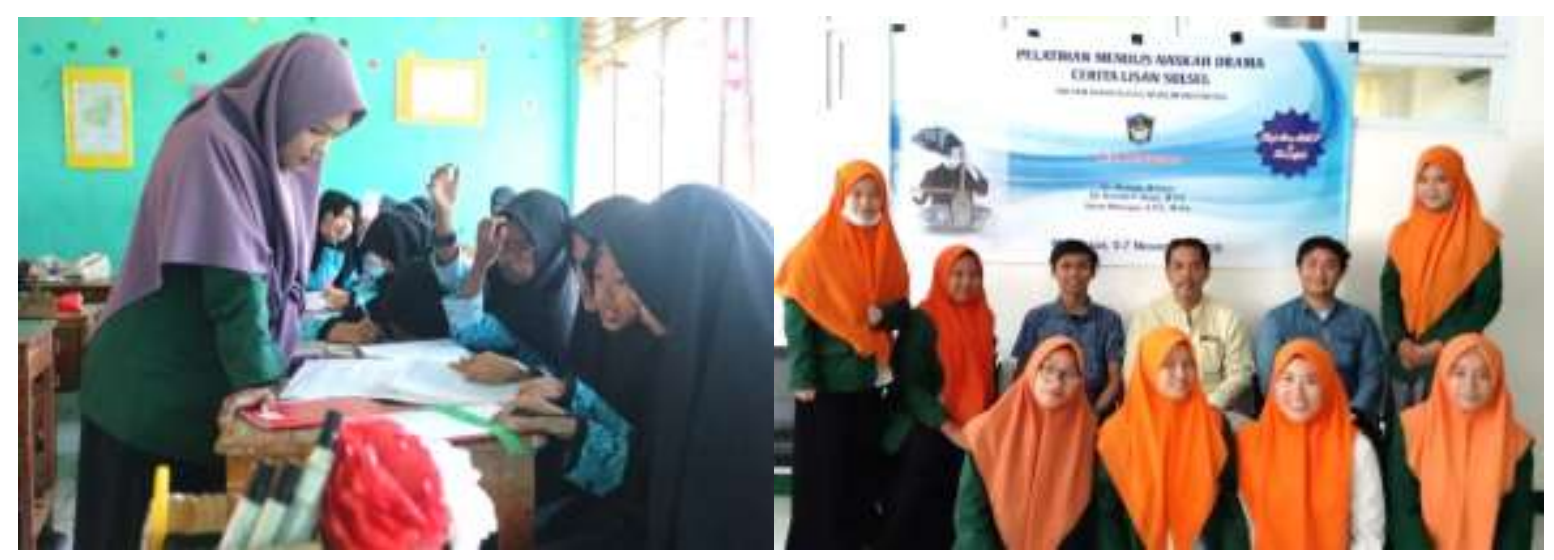

Gambar 2. Suasana pendampingan penulisan naskah drama dan tim pelaksana

Berdasarkan pengamatan saat kegiatan dilakukan, penyusunan naskah drama yang dibuat oleh siswa menunjukkan capaian tulisan yang belum menunjukkan hasil yang maksimal. Para siswa merasa masih belum mampu mentransfer cerita yang didengarkan ke dalam media tulisan atau ke dalam sebuah naskah drama. Hal yang berbeda justru ditunjukkan oleh para guru yang cukup antusias menyimak materi yang dipaparkan mengenai ragam cerita lisan Sulawesi Selatan dan pemanfaatannya sebagai bahan ajar, serta sebagai sarana pengembangan karakter siswa. 
Selain itu, persoalan lainnya yang juga ditemukan adalah siswa agak sulit membangun dialog dan penokohan cerita, serta dalam menciptakan kalimat dialog. Oleh karena itu, tim pelaksana PKM dan instruktur memberikan model pendampingan secara interaktif dan intensif dalam mengarahkan para siswa ketika menemukan kendala. Para peserta menunjukkan antusiasme yang cukup luar biasa dan yang hadir saat kegiatan berlangsung sudah sesuai dengan target peserta yang telah direncanakan.

\section{Simpulan dan Rekomendasi}

Secara keseluruhan, pelaksanaan kegiatan PKM Pelatihan Penulisan Naskah Drama dari Cerita Lisan Sulawesi Selatan yang dilaksanakan di MTs Negeri 2 Biringkanaya Makassar ini mendapat respon yang baik dari peserta yang menjadi mitra pengabdian masyarakat. Para peserta pelatihan antusias mengikuti kegiatan yang diberikan. Target jumlah peserta kegiatan yang direncanakan tercapai hingga $100 \%$ pada saat kegiatan berlangsung. Pihak sekolah dan para guru sangat mengapresiasi pelatihan ini karena kegiatan seperti ini belum pernah dilakukan di sekolah, sehingga pengetahuan siswa mengenai penulisan naskah drama dari cerita lisan atau sastra lokal daerah Sulawesi Selatan, dapat semakin bertambah. Sebagai tindak lanjut dari simpulan yang telah disajikan, diajukan saran agar sasaran yang dijadikan mitra kegiatan pelatihan penulisan naskah drama sebaiknya dimulai diberikan kepada para guru di lingkup kabupaten atau kecamatan, sehingga para guru yang telah dilatih dapat mentransfer pengetahuannya secara intensif kepada para siswa di sekolah masing-masing.

\section{Daftar Pustaka}

Amin, K. F. (2016). Sastra Klasik Bugis Makassar. Jogyakarta: Pustaka AQ.

Budiharto, R. A., \& Ramadani, T. (2018). Penggunaan Sastra Lingkungan untuk Membentuk Karakter Siswa Sekolah Dasar Kelas Rendah Peduli Lingkungan. Jurnal Abdimas BSI, 1(2), 180-185.

Mansyur, U. (2018). Korelasi Minat Baca dengan Kemampuan Menulis Karya Tulis Ilmiah Mahasiswa Pendidikan Bahasa Indonesia UMI. Multilingual: Jurnal Kebahasaan Dan Kesastraan, 17(1), 11-22.

Mansyur, U. (2019). Gempusta: Upaya Meningkatkan Minat Baca. Seminar Nasional Bahasa Dan Sastra II (Narasi II) FBS UNM. Retrieved from https://www.researchgate.net/publication/337671871

Muliadi, Firman, \& Amin, K. F. (2019). Folklore as Instrument to Internalize Character Values. Proceeding of The International Conference on Literature, 581-588. Retrieved from http:/ / www.jurnal.unsyiah.ac.id/ICOL/article/view/14507

OECD. (2019). PISA 2018 Results. Retrieved November 15, 2019, from https:// www.oecd.org/pisa/publications/pisa-2018-results.htm

Rohinah, M. N. (2011). Pendidikan Karakter Berbasis Sastra: Solusi Pendidikan Moral yang Efektif. Jogyakarta: Ar-Ruz Media. 